one, the result being that a certain proportion of sections, so far as the dental tissues were concerned, had to be discarded owing to the very obvious artifacts they showed. I have re-examined microscopically the sections, photographs of which Dr. Spriggs saw on the screen, and it may interest him to know that for the purposes of the investigation both of these sections were rejected for this reason. I might also point out that in investigating such a difficult subject one does not draw con. clusions from a comparison of any two sections but from a comparison of a very large number.

The photo-micrograms shown by Dr. D. Chalmers Watson were not from any of the three rats I referred to as having hypoplasic teeth; and, as stated in a previous letter, neither Mr. G. W. Watson nor I was able to detect any sufficiently constant variations in the tissues, hard or soft, to warrant us in concluding that there were any essential histological differences between the teeth of meat-fed and of bread-andmilk-fed rats.

Fdinburgh, Jan. 27th, 1907.

J. H. GibBs.

\section{THE PROPHYLAXIS OF CANCER AS IN- DICATED BY THE PARASITIC THEORY.}

To the Editors of THE LANOET.

SIRS, - No one can have followed the progress of cancer research in this and other countries without being impressed with the vast extent of the knowledge which has been acquired in recent years, and yet he must also be impressed by the present limitations of that knowledge and must feel how little progress has been made in the matter of actual dealing with the disease. In the course of this research certain facts relating to cancer seem to have come into special prominence of late. To the writer, as an outside observer, these seem to be the following : (1) the widespread and almost universal distribution of cancer; (2) the extraordinary powers of growth exhibited by the cancer cells within the body; (3) the great vitality exhibited by these cells without the body; and (4) the ever-increasing evidence that in a large proportion of cases of cancer infection is by direct inoculation from without.

These facts seem to throw some light on those portions of the life-history of cancer which hitherto have lain in obscurity. Of one part of that life-history we know something. We trace the primary growth presumably from a single cell. This by its rapid growth soon becomes a tumour containing thousands of cells, each of which when carried away by the lymph or blood may become a secondary growth. Thus by the end of life one cell has become a million, and then with the patient $s$ death they once more pass out of our sight. These facts to which I have referred seem, however, to indicate that the life-history of cancer does not end with the life-history of its host, but that long persisting in the bodies of the dead they may in all probability withstand the forces which destroy those tissues and in some resistant sporelike form become by slow degrees disseminated through the soil, carried by worms or birds, or by the deep water channt ls and thus account for the far-reaching distribution of the disease, its universality, and its widespread incidence. If this be so, it bears some analogy to the dissemination of tubercle bacilli, with their wide distribution in nature, their great resistant powers during extra-corporeal life, their somewhat difficult " adhesion" to the human host, and their powers of growth when once they gain access to that host.

In the present argument the cancer cell is regarded as the infecting agent. This is generally admitted to be the case when dissemination takes place within the body and the effect of radical operation strongly supports this view. Evidence has been brought forward to show the extraordinary powers of resistance to chemical agents, cold, \&c., of those cancer cells outside the body and the history of cancer-infected mice cages and of cancer houses is also in favour of their vitality being long maintained under such conditions. The primary incidence of cancer, so rarely on the lungs, but so commonly on external surfaces and on the alimentary tract at points of lowered vitality, or, again, at similar points where the blood stream might carry the virus, seems to indicate an infection by some relatively heavy organism, such as a cell, which is very widely distributed in nature, and which may, though with difficulty, be inoculated from food, clothing, or other means of contact, but which is hardly ever air-borne. The difficulty of inoculation bears resemblance to that of tubercle, only is much more marked. Once established, however, the powers of growth in the human body are far greater, but the tissue reaction excited is much less, this, again, being in favour of an infection due to some cellular organism closely resembling the body cells rather than to any extraneous micro-organism.

Finally, the contrast between the growth and multiplication of these cells within and without the body is most remarkable. Within we can trace the development from a single cell of the millions of cells represented by the secondary growths of " general dissemination." Without, while we have much evidence of the maintained vitality of the cancer cells, we know of no conditions under which they may continue to grow or to multiply. In the human subject we recognise that the virulence and infectivity of cancer vary in direct ratio to the rapidity of cell growth-in other words, to the number of cells. Is it not, therefore, reasonable to suggest that the widespread distribution of cancer is due to those myriads of cells committed to the soil with every patient dying from cancer, which subsequently by slow degrees become disseminated throughout nature?

Turning now to the question of the treatment of cancer, we feel that so far little progress has been made. No specific has yet been found and no antiserum has been obtained. Vaccine treatment in the case of mice seems to have given some result, but the difficulties of applying any such treatment to the human subject can readily be imagined and we still remain with only one cure-namely, early and complete excision. In recent years medical science has been increasingly occupied with the prevention rather than with the cure of disease. In the case of tubercle the importance of this is being more and more realised, as we see in the active crusade against the dissemination of tuberculous sputa and the efforts at isolation of advanced cases. No effort, however, seems to have been made to deal with that large source of tubercle bacilli which is found in the dead bodies of tuberculous patients which probably contributes largely to the distribution of the bacilli in nature. This may be of importance in tubercle, but from the arguments above brought forward is far more likely to be so in the case of cancer. Hence the writer would put forward a strong plea for an attempt at the prophylaxis of cancer, a goal which should not be unattainable if the above suppositions are correct. Granted this, the prophylaxis should be relatively easy, for in this case the great source of infection must be the bodies full of secondary growth which are committed to the soil at death, while other sources, such as cancerous discharges and infected excreta, are compara. tively unimportant and easily cealt with.

The cancer cells are readily destroyed by heat, and thus if cremation of all those dying from cancer can be legally enforced the great source of the disease will be eliminated, and it is not unreasonable to hope that by such methods a gradual diminution in the frequency of the disease or even its ultimate eradication may be attained. The writer can lay no claim to any share in the work of cancer research which has been carried on with so much ability and perseverance, but having followed its progress with the deepest interest he ventures to bring forward these suggestions which have been prompted by the work of others.

$$
\text { I am, Sirs, yours faithfully, }
$$

$$
\text { H. 'V. WENHAM. }
$$

St. Bartholomew's Hospital, E.C., Jan. 23rd, 1907.

\section{ELECTRIC LIGHT IN MARYLEBONE.}

\section{To the Editors of THE LANCET.}

SIRS,--Your reference to the failure of the electric light in Marylebone within the past few weeks and your warning to surgeons undertaking to perform operations with the aid of artificial light within the limits of the borough to provide against the recurrence of such a contingency is extremely opportune. However, the statement that while such events are unusual in other parts of London they have been frequent in Marylebone since the council undertook the lighting is more open to question. As a user of electric light, both under the old régime and since it has been taken over by the borough, I am in a position to say which is the greater sinner. It used to be a matter of frequent and almost weekly occurrence. Indeed, the failures were so frequent that a deputation of medical practitioners waited upon the council and asked them to take some action to put an end to 
or mitigate what was described as a nuisance and a positive danger. One eminent surgeon went on to describe how a day or so previously, while he was performing a serious operation on a child, the light had suddenly gone out and how he had grasped the severed end of an artery between finger and thumb while with the other hand he groped for his waistcoat-pocket for a wax vesta to give some light while candles were being procured.

It was this that largely influenced me as a member of the borough council in supporting the proposal that the municipal authorities should take over the electric lighting of the borough. I am not defending them; they may have acted nnwisely in the matter, but it is as well to remember that great pressure was brought to bear on them at the time by a large and important section of the consumers, including the surgeons in the district.

I am, Sirs, yours faithfully,

Thayer-street, Manchester-square, W. M. C. WALSHE.

\section{AMYL NITRITE IN HAMOPTYSIS.}

To the Editors of THE LANOET.

SIRs,-Permit me to make a final reply to the last communication of Dr. Francis Hare in THE LANCET of Jan. 19th. I have not been guided by preconceived theories but by clinical facts respecting the hæmostatic action of amyl nitrite and references in the literature to such facts were cited in my last letter. Dr. Hare expresses correctly my theory of action of the drug in question. The fact that the drug is equally efficacious whether given intravenously, by the mouth, or by inbalation is no evidence in contravention of my theory. Chloroform whether administered by inhalation or through other portals is capable of exercising its narcotic properties, and like amyl nitrite may excire profound reflex phenomena by virtue of its local irritant action on the nasal mucosa. Such phenomena range from coughing to cardiac inhibition. Because the hæmorrhage following the removal of parovarian cysts and that of ectopic gestation is controlled by amyl nitrite is no evidence in refutation of my theory until it has been demonstrated that in the structures implicated there are no muscular fibres. Finally, respecting the vaso-motor hypothesis advocated by Dr. Hare in explanation of the mechanism of the asthmatic paroxysm, if the hypothesis in question were correct, then amyl nitrite would in its action fulfil the requirements of the old principle-viz., "Naturam morborum ostendunt ouratione." The fact is that amyl nitrite is rarely efficacious, even temporarily so, in inhibiting a paroxysm, and I believe that anyone who has used it for this purpose will substantiate my statement. The failure of action is evident. In asthma, as $I$ have shown elsewhere, the longitudinal fibres of the bronchial musculature are enfeebled; hence the action of amyl nitrite is correspondingly diminished. In hæmoptysis the action of the drug is more forcibly expressed, insomuch as we assume that the muscular tonicity of the bronchial musculature is not compromised.

$$
\text { I am, Sirs, yours faithfully, }
$$

Paris, Jan. 22nd, 1907. Dr. ALBERT ABRAMs.

\section{THE TREATMENT OF CICATRICES.}

To the Editors of THE LANCET.

SIRS,- I fear we do not give the attention to this subject that it deserves, both from the annoyance and disability occasioned by scars, especially adherent ones, and the great relief that may be afforded by suitable treatment. I thought these facts were pretty well understood, but two recent cases, both treated at large hospitals here, suggest that one may venture to draw attention to the subject again. In the first case a dock labourer had suffered an extensive laceration of the outer side of the leg and healing had left a scar two or three inches across. The scar was very thin, of a clazed surface, a bright red in colour, and so adherent to the underlying fascia that the patient was unable to follow his occupation owing to pain and lameness on movement. I introduced a tenotome beneath the skin and separated the cicatrix from the fascia beneath it completely, leaving no wound but the puncture of the tenotome. The man was kept up and by walking about and gentle movements of the skin further adhesions were prevented. He was soon able to resume work and the bright glazed skin became almost normal in appearance, though $I$ confess that owing to the size of the cicatrix I feared sloughing would occur.
In another case a man had had the superficial flexor tendons of the forearm divided and the cicatrix in the skin covering the wound became adherent to the tendons and fascia over an extent of some three inches. He was unable to bend his fingers in the slightest degree on his discharge from hospital. He then presented himself at another of our largest hospitals and was subjected to prolonged treatment, so he says, by elaborate mechanical appliances. Being still unable to flex his fingers and his hand being entirely useless he came to the Bootle Borough Hospital and begged that the hand might be amputated, so that be might replace it with a more useful hook. I declined to oblige him but separated the scar subcutaneously from the tendons beneath it. This, with a subsequent freeing of fresh adhesions by my house surgeon, has enabled him to flex his fingers to such an extent that he is able to get a slight grasp with them, powerful as far as it goes, and to do his work.

I have drawn attention to these cases because they had both been under hospital treatment and had both been discharged suffering from serious disability that was readily overcome. It appears as though we were neglecting some old teaching on the treatment of cicatrices. We should do well to remember how much can be done for these cases and where unsightliness is the only difficulty how astonishingly the damaged skin may regain a normal appearance when separated from adhesions that strangle, rather than develop, ts blood-supply.-I am, Sirs, yours faithfully,

Liverpool, Jan. 21st, 1907. GEORGE A. HAWKINS-AMBLER.

\section{SPIROGRAPHS OR NASAL "BREATH PICTURES."}

To the Editors of THW LANCET.

SIRs, - Under the above heading Dr. Wyatt Wingrave in his letter in THe LANCET of Jan. 26th, p. 253, described a spirograph made of vulcanite designed to test the degree of actual or relative nasal patency. Aqueous vapour exhaled through the nostrils is condensed on the cool surface of the vulcanite and a fleeting "breath picture" thus obtained, which may be temporarily fixed by lightly powdering the surface with calcined magnesia or fine starch.

It may be of interest to describe the pneumodograph, designed by Courtade of Paris, by means of which he obtains permanent records of the degree of respiratory nasal sufficiency. The instrument consists essentially of two plates of glass, graduated in squares, fixed at right angles to each other, $T$, by means of detachable catches. One plate of the pneumodograph is held horizontally against the upper lip a short distance below the nostrils, consequently the other piate hangs vertically downwards a few inches in front of the mouth. The patient is asked to breathe several times in the manner habitual to him. Condensation of aqueous vapour on the horizontal plate records the degree of nasal patency and a similar condensation on the vertical plate indicates the presence and degree of buccal respiration. Taken in connexion with one another the two spirographs may be used as a practical test of nasal respiratory sufficiency in any particular case, which is often a more useful factor than the degree of nasal patency alone. Permanent records are readily made by pressing sheets of paper specially im. pregnated with safranin on the surface of the glass plates, the pink colouring matter being liberated by the condensed aqueous vapour. Courtade's pneumodograph is made by Collin of Paris and can be obtained in London through Messrs. Mayer and Meltzer.

I am, Sirs, yours faithfully,

Birkdale, Jan. 28th, 1907. ALFRED ERNEST BuRROUGHS.

\section{THE ACTION OF POTABLE SPIRITS ON METAL.}

To the Editors of THE LANCET.

SIRS,--In THE LANCET of Dec. 29th last, p. 1821, I observe you have a note on brandy being contaminated with copper Might I be permitted to mention that I had a flask with whisky sent me by a sportsman some years ago? The flask had been filled and was daily carried to the moor, but no occasion had arisen for using the contents for over two weeks, and when the valet was in the act of filling a glass the colour was observed to have changed and had become turbid and dark. The gentleman would not 